\title{
Paediatric robotic surgery and urology: where are we?
}

\section{Simon Clarke ${ }^{1}$}

Published online: 3 June 2019

(c) The Author(s) 2019

Keywords Robotics $\cdot$ Paediatric surgery $\cdot$ Evidence-based

\section{Introduction}

The uptake of robotic surgery by paediatric surgeons has been slower compared to our adult counterparts (Fig. 1). $3 \mathrm{~mm}$ minimally invasive neonatal surgery is challenging with the current robotic platforms and few neonatal cases have been reported [1-3]. The improved dexterity and lower complication rate afforded by robotic assisted surgery is the gold standard for adult procedures such as prostatectomy [4] and increasingly colorectal surgery [5]. In paediatrics, reconstructive procedures that involve prolonged and advanced suturing skills, such as pyeloplasty and fundoplication, were expected to be most applicable.

This article aims to provide an overview of the current updated levels of evidence for some of the main procedures undertaken by paediatric surgeons and urologists using robotic technology.

\section{Pyeloplasty}

The first robotic pyeloplasty was described in 2006 [6]. A decade later Cundy et al. [7], demonstrated through a metaanalysis similar outcome results when comparing robotic to the open approach though no level 1 evidence data were evident. The main difference between the two approaches was operative time and cost, with robotic significantly slower and more expensive. Other multi-centre studies since then have shown some reduction in hospital stay $[8,9]$ but a multi-centre prospective RCT trial would be needed to accurately compare the laparoscopic and the robotic approach.

Simon Clarke

simon.clarke@chelwest.nhs.uk

1 Chelsea Children's Hospital, Chelsea and Westminster Healthcare NHS Fdn Trust, 369 Fulham Road, London SW10 9NH, UK
The power of such a study would require a large number of patients, as outcome differences between both modalities is likely to be small.

Ureteral re-implantation and ureteroureterostomy have been shown to be comparable in a few small series [10-14].

\section{Vesico-ureteric reimplantation (VUR)}

Fewer studies exist in this field. Kasturi et al. demonstrated excellent outcomes for vesico-ureteric reflux using a robotic assisted approach [15]. Smith et al. compared outcomes of resolution of VUR with the open approach. They found no significant differences when using the robot though complications such as bladder and ureteral leak did seem to be more frequent [16]. The open group demonstrated a higher rate of post-operative bladder spasm and therefore the overall frequency of complications was described as equivocal. Both reports discuss a shorter length of stay when compared to the open approach.

\section{Nephrectomy and hemi-nephrectomy}

The adult literature produced a meta-analysis describing favourable results with robotic nephrectomy compared to laparoscopic [17]. A lower conversion rate to radical nephrectomy, renal function using indexed estimated glomerular filtration rate, a shorter length of hospital stay, and a shorter warm ischemia time, all were improved with robotic procedures. In 2015 Till et al., also published a metaanalysis examining eleven paediatric studies that reported on the differences between conventional laparoscopy compared to laparoscopic single site and robotic surgery, in relation to partial and total nephrectomy [18]. The paediatric data did not offer any clear advantages over conventional laparoscopy and the operative time and cost was significantly increased. 


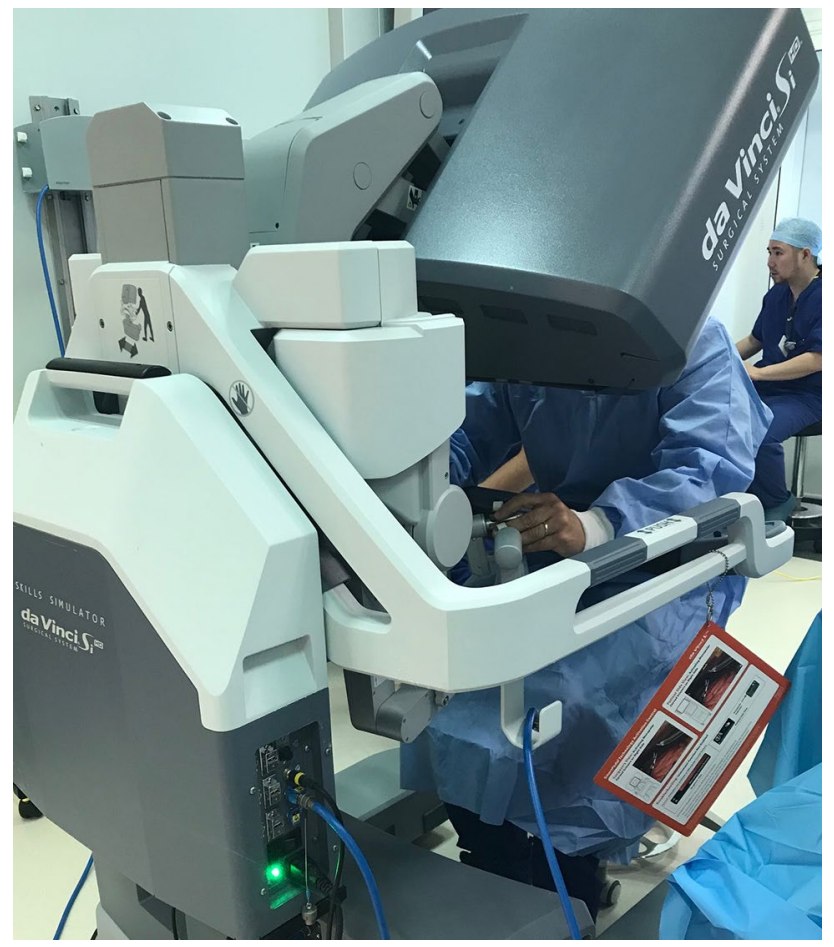

Fig. 1 View of the console for robotic procedures

There were, however, far few patients in the paediatric data studies.

\section{Anti-reflux surgery}

Laparoscopic anti-reflux surgery in children has very favorable outcomes in children when compared to the open approach [19].

The majority of publications involve the fundoplication. The demand on the surgeon for this procedure in terms of suturing is considerably less than that of a reconstructive urological procedure though awkward angles and hiatal hernia reconstruction can be more involved, hence the robotic approach could offer advantages (Figs. 2, 3). Darzi's group in 2015 published a meta-analysis [20] which did not demonstrate any significant differences though a need for dilatation following a presumed tight wrap, was more frequent in the laparoscopic and robotic procedures. There were no level-1 evidence studies.

A similar group in Leeds also reviewed a prospective database to examine the learning curve for robot-assisted fundoplication [21]. Statistically significant transitions beyond the learning phase were observed at cases 42, 34, and 37 for docking, console and total operating room times, respectively. A steep early learning phase for docking time was overcome after 12 cases.

\section{Cholecystectomy and splenectomy}

No published studies to date have demonstrated a significant benefit to the paediatric patient when comparing robotic with laparoscopic. Unlike fundoplication, no direct comparisons
Fig. 2 Operation room view and team setup for robotic procedures

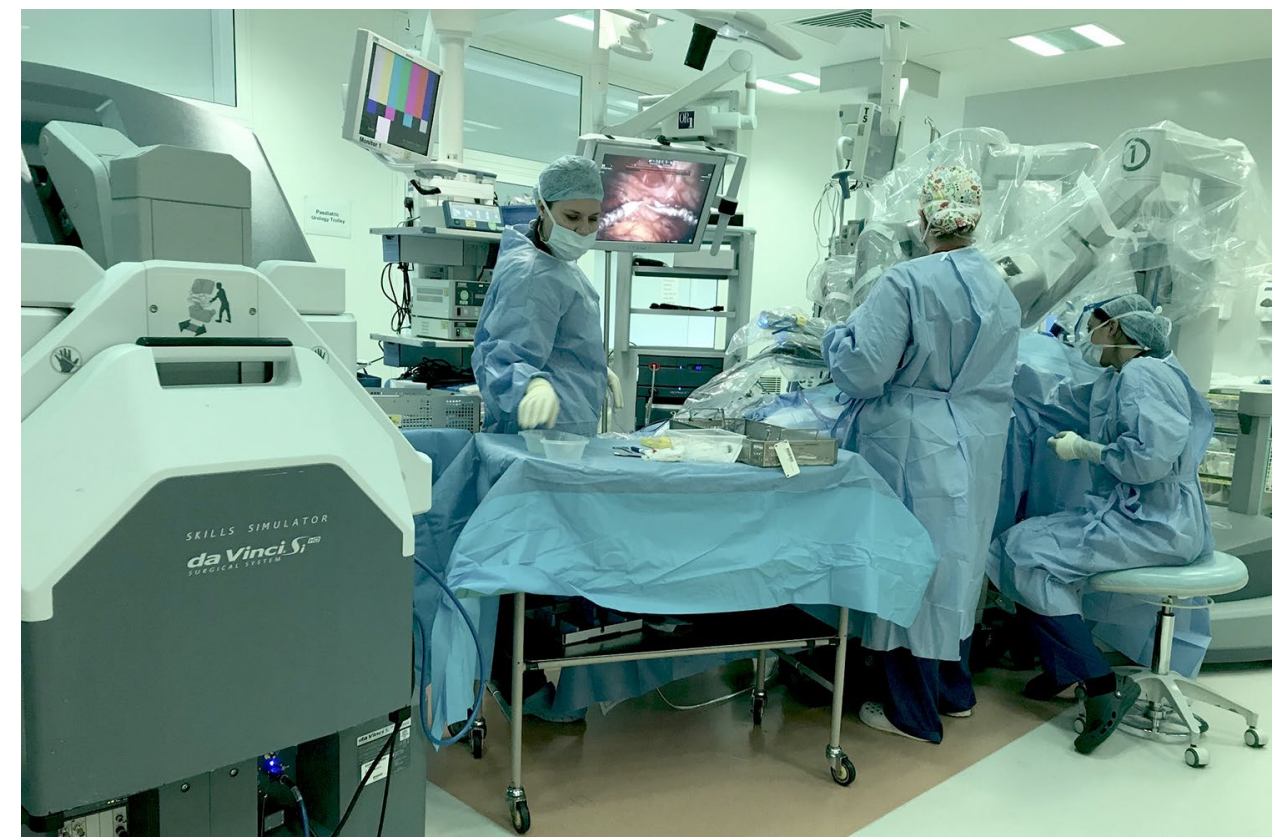




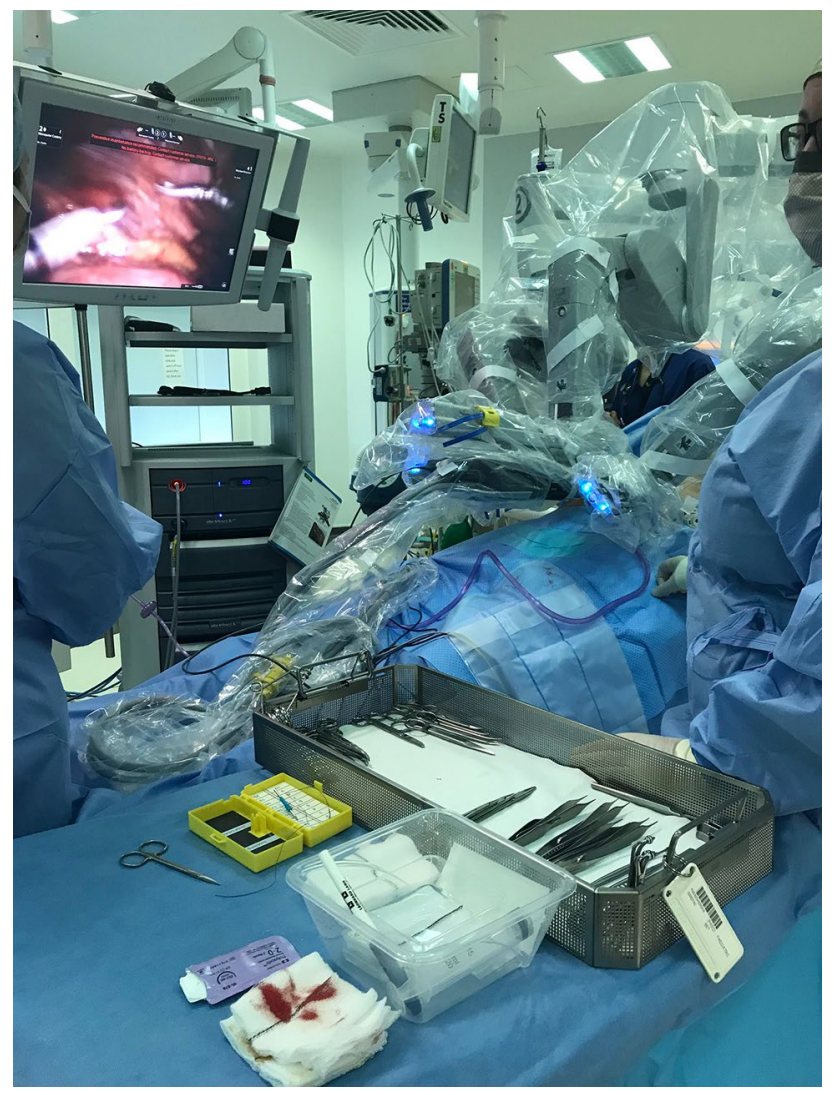

Fig. 3 View of the robotic arms during a laparoscopic fundoplication

have been made and recent data so far consist mostly of case series $[15,22]$. The main advantage that these cases seem to offer is that of useful training experience for robotic skills.

\section{Hepaticoenterostomy}

Roux-en-Y hepaticoenterostomy for choledochal cyst excision involves delicate portal dissection and a sutured anastomosis. Robotics again would seem to offer the paediatric hepatobilary surgeon significant advantages though to date there are few case reports [23, 24].

Case reports and small series have been published that describe a range of other general paediatric surgery procedures such as diaphragmatic hernia repair [2, 25], Heller's cardiomyotomy for achalasia [26, 27], duodenojejunostomy for SMA syndrome [28], duodenal atresia repair [3], and anorectal pull-through for anorectal malformations [15]. Currently these case studies are mostly demonstrating feasibility rather than equivalence/superior outcomes.

\section{Cost effectiveness of robotic surgery}

The cost of a setting up a robotic surgical program is significant. Even once established, the ongoing costs can be prohibitive to many paediatric units. Various publications examine the different procedures when compared to standard laparoscopy. A group from Indiana examined open and robotic pyeloplasty over a 9-year period in 18 American children's hospital [29]. They found an increased cost per case by nearly $\$ 4000$ for robotic surgery. The length of stay was shorter, but this still did not offset the significant procedural cost difference. The increased charges were cited as mainly operating theatre and anaesthetic charges. As patents expire and an increasing competitive market grows, outlay costs will no doubt reduce.

\section{Conclusions}

Robotic procedures in paediatric surgery are increasingly reported. The Patient Health Information System in the US reports an increase of $19.8 \%$ year on year since 2008 [29]. Financial restrictions in many European public health markets will likely demonstrate a reduced growth when compared to the US. Over the next decade, the introduction of new, more affordable robotic platforms is likely to alter this.

Open Access This article is distributed under the terms of the Creative Commons Attribution 4.0 International License (http://creativeco mmons.org/licenses/by/4.0/), which permits unrestricted use, distribution, and reproduction in any medium, provided you give appropriate credit to the original author(s) and the source, provide a link to the Creative Commons license, and indicate if changes were made.

\section{References}

1. Meehan JJ, Sandler A (2008) Pediatric robotic surgery: A singleinstitutional review of the first 100 consecutive cases. Surg Endosc Other Interv Tech 22:177-182

2. Meehan JJ, Sandler A (2007) Robotic repair of a Bochdalek congenital diaphragmatic hernia in a small neonate: robotic advantages and limitations. J Pediatr Surg 42:1757-1760

3. Meehan JJ (2007) Robotic repair of congenital duodenal atresia: a case report. J Pediatr Surg 42:E31-E33

4. Shah AA, Gahan JC, Sorokin I (2018) Comparison of robotassisted versus open simple prostatectomy for benign prostatic hyperplasia. Curr Urol Rep 19:71-81

5. Dolejs SC, Waters JA, Ceppa EP, Zarzaur BL (2017) Laparoscopic versus robotic colectomy: a national surgical quality improvement project analysis. Surg Endosc 31:2387-2396

6. Kutikov A, Nguyen M, Guzzo T, Canter D, Casale P (2006) Robot assisted pyeloplasty in the infant-lessons learned. J Urol 176:2237-2239

7. Cundy TP, Harling L, Hughes-Hallett A, Mayer EK, Najmaldin AS, Athanasiou T et al (2014) Meta-analysis of robot-assisted vs 
conventional laparoscopic and open pyeloplasty in children. BJU Int 114:582-594

8. Silay MS, Spinoit AF, Undre S, Fiala V, Tandogdu Z, Garmanova $T$, et al (2016) Global minimally invasive pyeloplasty study in children: results from the pediatric urology expert group of the European Association of Urology Young Academic Urologists working party. J Pediatr Urol 12:229e1-229e7

9. Chan YY, Durbin-Johnson B, Sturm RM, Kurzrock EA (2017) Outcomes after pediatric open, laparoscopic, and robotic pyeloplasty at academic institutions. J Pediatr Urol 13(49):e1-49

10. Marchini GS, Hong YK, Minnillo BJ, Diamond DA, Houck CS, Meier PM et al (2011) Robotic assisted laparoscopic ureteral reimplantation in children: case matched comparative study with open surgical approach. J Urol 185:1870-1875

11. Harel M, Herbst KW, Silvis R, Makari JH, Ferrer FA, Kim C (2015) Objective pain assessment after ureteral reimplantation: Comparison of open versus robotic approach. J Pediatr Urol 11(82):e1-8

12. Bansal D, Cost NG, Bean CM, Vanderbrink BA, Schulte M, Noh PH (2014) Infant robot-assisted laparoscopic upper urinary tract reconstructive surgery. J Pediatr Urol 10:869-874

13. Leavitt DA, Rambachan A, Haberman K, DeMarco R, Shukla AR (2012) Robot-assisted laparoscopic ipsilateral ureteroureterostomy for ectopic ureters in children: description of technique. J Endourol 26:1279-1283

14. Lee NG, Corbett ST, Cobb K, Bailey GC, Burns AS, Peters CA (2015) Bi-Institutional comparison of robot-assisted laparoscopic versus open ureteroureterostomy in the pediatric population. J Endourol 29:1237-1241

15. Al-Bassam A (2010) Robotic-assisted surgery in children: advantages and limitations. J Robot Surg 4:19-22

16. Kasturi S, Sehgal SS, Christman MS, Lambert SM, Casale P (2012) Prospective long-term analysis of nerve-sparing extravesical robotic-assisted laparoscopic ureteral reimplantation. Urology 79:680-683

17. Choi JE, You JH, Kim DK, Rha KH, Lee SH (2015) Comparison of perioperative outcomes between robotic and laparoscopic partial nephrectomy: a systematic review and meta-analysis. Eur Urol 67(5):891-901
18. Till H, Basharkhah A, Hock A (2016) What's the best minimal invasive approach to pediatric nephrectomy and heminephrectomy: conventional laparoscopy (CL), single-site (LESS) or robotics (RAS)? Transl Pediatr 5:240-244

19. McHoney M, Wade AM, Eaton S, Howard RF, Kiely EM, Drake DP et al (2011) Clinical outcome of a randomized controlled blinded trial of open versus laparoscopic Nissen fundoplication in infants and children. Ann Surg 254:209-216

20. Cundy TP, Harling L, Marcus HJ, Athanasiou T, Darzi AW (2014) Meta analysis of robot-assisted versus conventional laparoscopic fundoplication in children. J Pediatr Surg 49:646-652

21. Mahida JB, Cooper JN, Herz D, Diefenbach KA, Deans KJ, Minneci PC, McLeod DJ (2015) Utilization and costs associated with robotic surgery in children. J Surg Res 199:169-176

22. Alqahtani A, Albassam A, Zamakhshary M, Shoukri M, Altokhais T, Aljazairi A et al (2010) Robot-assisted pediatric surgery: how far can we go? World J Surg 34:975-978

23. Meehan JJ, Elliott S, Sandler A (2007) The robotic approach to complex hepatobiliary anomalies in children: preliminary report. J Pediatr Surg 42:2110-2114

24. Woo R, Le D, Albanese CT, Kim SS (2006) Robot-assisted laparoscopic resection of a type I choledochal cyst in a child. J Laparoendosc Adv Surg Tech A 16:179-183

25. Meehan JJ, Torres JE (2008) Robotic repair of Morgagni congenital diaphragmatic hernia in an infant. J Robot Surg 2:97-99

26. Chaer RA, Jacobsen G, Elli F, Harris J, Goldstein A, Horgan S (2004) Robotic-assisted laparoscopic pediatric Heller's cardiomyotomy: initial case report. J Laparoendosc Adv Surg Tech A $14: 270-273$

27. Altokhais T, Mandora H, Al-Qahtani A, Al-Bassam A (2016) Robot-assisted Heller's myotomy for achalasia in children. Comput Assist Surg (Abingdon) 21:127-131

28. Bütter A, Jayaraman S, Schlachta C (2010) Robotic duodenojejunostomy for superior mesenteric artery syndrome in a teenager. $\mathrm{J}$ Robot Surg 4:265-269

29. Bennett WE Jr, Whittam BM, Szymanski KM, Rink RC, Cain MP, Carroll AE (2017) Validated cost comparison of open vs. robotic pyeloplasty in American children's hospitals. J Robot Surg 11:201-206 